\title{
EFFECTS OF MARTIAL ARTS TRAINING ON SELECTED PSYCHO- PHYSIOLOGICAL VARIABLES OF MALE BASKETBALL PLAYERS
}

\author{
Dr. R. Soundara \\ Rajan* \\ Assistant Director of Physical Education, PSG College of Arts \& Science, \\ Coimbatore. ${ }^{*}$ Corresponding Author
}

Dr. B. Navaneethan Director of Physical Education, PSG College of Arts \& Science, Coimbatore.

ABSTRACT Basketball is considered one of the most popular sports in the world as the third fastest game played in short court surfaces. In high level competitions, very specifically during the matches between the challenging teams, because of stress players may have an opportunity to loose their mental toughness, perception ability, concentration and apprehending the fellow players moves. As a result of this player finds it difficult in executing the fundamental skills in time which affects the ultimate aim of the team. In this situation, when finding the alternative means and methods to develop the physical, mind and game based physical activity concurrently; it was observed that these characteristics are correlating with the event of Taekwon-do which is one of the martial activities. The study consisted of 24 male basketball players from PSG College of Arts \& Science, Coimbatore. Their age ranged from 18 to 25 years. The Psychophysiological variables of VO2 max, Resting pulse rate and Competitive sport Anxiety Inventory-2 (CSAI-2), developed by Martens, Vealey, \& Burton (1990) were used. Subjects were randomly assigned to either a martial arts training experimental group, or a no martial arts training control group. The experimental group were given training for 3 days a week and for 6 weeks in total. Paired t-tests were used to test the effect of treatment groups individually between pre and post-tests of all the groups on variables used in the present study. The result of the study reveals that there was significant difference in 0.05 levels of VO2 max, Resting pulse rate and Competitive sport Anxiety among the male basketball players.

\section{KEYWORDS : Martial arts training, VO2 max, Resting pulse rate, competitive anxiety}

\section{INTRODUCTION}

Basketball is considered one of the most popular sports in the world. It is played and watched by more people than any game, extending to more than 170 countries around the globe. Dr. James Naismith is known world-wide as the inventor of basketball. Basketball stands as the third fastest game played in short court surfaces. As a game of agile and explosive event in nature, a player is in need of basic fitness and motor components along with skill based drills to master in the fundamental skills and execute the same in a well defined format. For this, players have been trained with martial arts training. In high level competitions, very specifically during the matches between the challenging teams, because of stress players may have an opportunity to loose their mental toughness, perception ability, concentration and apprehending the fellow players moves. As a result of this player finds it difficult in executing the fundamental skills in time which affects the ultimate aim of the team. In this situation, when finding the alternative means and methods to develop the physical, mind and game based physical activity concurrently; it was observed that these characteristics are correlating with the event of Taekwon-do which is one of the martial activities.

Martial arts were developed in ancient Asia as an essential form of combat. In recent years, martial arts have experienced substantially widespread growth as a combative sport, selfdefense system, physical fitness (Hallander, 1987), and mental control training (Columbus \& Rice, 1991; Daniels \& Thornton, 1990; Finkenberg, 1990; Law, 2004; Richman \& Rehberg, 1986; Spear, 1989; Trulson, 1986).

The first glance of the martial art seems to be set of physical skills, but the real goal is to condition the mind. It is the mind that has to learn to act quickly. The mental benefits of martial arts are possibly more significant than the physical. As for as Taekwon-do is concerned, it can be characterized as a series of movement sequences involving punching, kicking, blocking, jumping, twisting and leaping performed at high intensity. Further, for mastering in this event an individual has to develop functional flexibility, explosive power, and limbs speed over maximal strength and a high level of anaerobic power and endurance. Thus the Taekwon-do seemed to be a highly resembling event with the game of basketball. Hence, it is believed that, to enhance the efficiency of available physical training modules in developing the physical and motor components and to avail the needed factors to excel in the game of basketball, implicating the martial arts in addition to their physical training will be a worthwhile and a right training module for the game of basketball. To study the effects of varied combinations of training with martial arts in the development of components that are needed for excelling in basketball.

Taekwondo's acceptance as an Olympic sport, research has been done into the anxiety feelings surrounding the sport side of Taekwondo. Some competitors feel extremely anxious prior to their performance, while others are not so concerned. Some research has shown that the level of anxiety does not effect sparring performance, while other research found that competitors with lower levels of pre-competition anxiety are more likely to win their matches. However, research has shown that males competing in Taekwondo have significantly higher anxiety prior to competing than males competing in other sports, with females having the same level of anxiety whether competing in Taekwondo or other sports.

Pre-sparring anxiety may be more anxiety provoking compared to other sports because the Taekwondo competitor must fight another person. Anticipation of combat heightens arousal. Since tournament sparring is an individual event, rather than a team sport, the anxiety of competing is not shared amongst numerous players. Also, although a Taekwondo competitor has a coach on the sidelines, the interaction between the coach and the competitor is minimal compared to other sports. Even though the anxiety related to the sport side of Taekwondo has produced inconsistent findings, consistent long-term training has been found to actually reduce anxiety associated with everyday living. This may be because, as students become more confident in their abilities to defend themselves, they have less fear of bodily harm or being intimidated.

\section{METHODS}

Selection of subjects

The purpose of the study was to find out the effect of martial 
arts training on selected psycho-physiological variables of male basketball players. To achieve the purpose of the study twenty four male basketball players were selected from PSG College of Arts \& Science, Coimbatore. Their age was ranged from 18 to 25 years. The purpose of the present study was explained to them clearly where by their consent to serve as samples were obtained. The present study is an experimental one and to test the effects of varied forms of intervening strategies, the care was taken in distributing the samples to each experimental group. For this, the selected samples $(\mathrm{N}=24)$ were divided into two equal groups. Group I was considered as martial arts training group (MATG) in which they underwent progressive takewondo practices. Group II was considered as control group they are doing the regular physical \& skill practice under the control of investigator. The experimental group were given training for 3 days a week and for 6 weeks in total.

\section{Selection of variables}

The research scholar reviewed the available scientific literature and had discussions with experts in the field of physical education and sports coaching to identify the components underlying psycho physiological variables of basketball players. Based on the opinions of experts, and from the findings of the earlier studies in the field of training in basketball, the following factors were identified and considered as variables for the present study. Thus, the variables selected for the present study were: $\mathrm{VO}_{2}$ max, resting pulse rate, cognitive anxiety, somatic anxiety and self confidence.

\section{Resting Pulse Rate}

The resting heart rate of each subject was recorded in the early morning after getting out of bed and sit at rest comfortably in a chair for few minutes. The resting heart rate was obtained through auscultation i.e. using the bell of the stethoscope was placed to the left of the sternum just above the level of the nipple. Then the stop watch was started with the heart beat. Counted the first beat as zero and continued for 30 seconds. This procedure was repeated on three separate mornings. Resting heart of the subjects was recorded on three successive mornings. The average of the three recordings was arrived at and recorded as the subjects resting heart rate. The unit of measurement was initially taken for 30 seconds and the beats per minute of the subjects were calculated by doubling the number of beats to arrive at and per minute calculation. (Nieman, 1995)

\section{$\mathrm{VO}_{2} \operatorname{Max}$ (3 Minutes Step Test)}

For the purpose of the maximum conception of oxygen was determined by this test. The step test was preferred on a stool of 16.2 inches height for a total duration of 3 minutes at the rate of 22 cycles per minute which was set by a metronome. After completion of exercise, the subject was asked to remain standing and the carotid pulse rate was measured from 5 - 20 seconds of the recovery period. This 15 second pulse rate was converted into beats per minute and the following equation was used to predict the maximum oxygen uptake capacity.

111.33 - (0.47x Recovery heart rate in beats per minute).

\section{Competitive Sport Anxiety Inventory - 2}

Competitive state anxiety was assessed by using the Competitive State Anxiety Inventory - 2 (CSAI-2, Martens et al. 1990) which is a self report, psychometric state anxiety inventory, consisting of 27 items. The CSAI-2 normally takes less then five minutes to complete and was administered ten minutes before competition and practice session. Before allowing subjects to begin completing the CSAI-2, instructions were explained, and researchers ensured that all instructions were completely understood. State anxiety was measured by the Competitive State Anxiety Inventory - 2 (CSAI - 2) (Martens et al 1990). The CSAI - 2 assess two components of state anxiety, cognitive worry and somatic anxiety, and a related constricts self-confidence.
The CSAI - 2 contains 9 items that represent each sub - scale. Thus, each sub - scale has a range from 9 to 36 . Higher scores on cognitive and somatic anxiety indicate higher levels of anxiety whereas higher scores on self-confidence sub-scale correspond to higher levels of self-confidence (Martens et al. 1990 and Mckay et al. 1997).

\section{Training Programme}

Experimental groups trained three days per week on nonconsecutive days (Monday, Wednesday and Friday) for six weeks under carefully administered and controlled conditions/ prior to each training session, all subjects participated in a 10 minute warm - up period which included jogging at a self selected comfortable pace. After the warm up session the subjects performed selected Martial arts training exercises on Monday, Wednesday and Friday for 30 minutes. From $1 \mathrm{~s}^{\mathrm{t}}$ week to $2^{\text {nd }}$ week, all subjects performed $1-2$ sets of 15 to 20 repetitions on the following exercises: dodging strike, downward strike, front strike, inward strike, elbow strike, side back strike, side front thrust, downward kick, vertical kick, side checking kick. From $3^{\text {rd }}$ week to $4^{\text {th }}$ week, all subjects performed 1-2 sets of 15-20 repetitions on the following exercise and in addition to one set of 15 repetitions as in $1^{\text {st }}$ week to $4^{\text {th }}$ week: outward strike, downward thrust, side thrust, ground thrust, back elbow thrust, side kick, turning kick, upward kick, rising kick and front rising kick. From $5^{\text {th }}$ week to $6^{\text {th }}$ week, all subjects performed 1-2 sets of 15-20 repetitions on following exercise and in addition to one set of 15 repetition as in $1^{\text {st }}$ week to $4^{\text {th }}$ and $5^{\text {th }}$ week to $8^{\text {th }}$ week: horizontal strike, horizontal thrust, back twin elbow thrust, front snap kick, back kick, stamping kick, grapin kick, twisting kick, side rising kick and hooking kick.

\section{RESULTS}

The study was designed to find out the effect of martial arts training on psycho- physiological variables of male basketball players. The test the objective framed in the present study the data collected on variables of $\mathrm{VO}_{2}$ max, resting pulse rate, cognitive anxiety, somatic anxiety and self confidence. As one of the objectives of the present study was to test the effects of martial arts training on $\mathrm{VO}_{2}$ max, resting pulse rate and competitive anxiety, the initial test means and final test means were tested treatment wise by using the paired sample t-test. Analysis of covariance was used to test the adjusted mean differences among the treatment groups. Then they obtained ' $F$ ' ratio is tested at 0.05 level of significance.

Table 1 The difference between the results of the initial and final measuring the Martial arts training group

\begin{tabular}{|c|c|c|c|c|c|c|c|}
\hline Test & Measuring & Mean & Std.dev. & $\mathbf{N}$ & Diff. & $t$ & \\
\hline \multirow[t]{2}{*}{$\mathrm{Vo}_{2} \mathrm{Max}$} & Initial & 38.35 & 1.47 & 15 & \multirow[t]{2}{*}{1.36} & \multirow[t]{2}{*}{3.343} & \multirow[t]{2}{*}{$.0 c$} \\
\hline & & 36.99 & 1.22 & 15 & & & \\
\hline \multirow{2}{*}{$\begin{array}{c}\text { Resting } \\
\text { Pulse Rate }\end{array}$} & & 73.08 & 1.78 & 15 & \multirow[t]{2}{*}{2.58} & \multirow[t]{2}{*}{13.385} & \multirow[t]{2}{*}{.0} \\
\hline & Fin & 70.50 & 1.73 & 15 & & & \\
\hline \multirow{2}{*}{$\begin{array}{l}\text { Cognitive } \\
\text { Anxiety }\end{array}$} & Init & 22.83 & 1.64 & 15 & \multirow[t]{2}{*}{2.91} & \multirow[t]{2}{*}{11.222} & \\
\hline & $\mathrm{F}$ & 19.92 & 1.68 & 15 & & & \\
\hline \multirow{2}{*}{$\begin{array}{l}\text { Somatic } \\
\text { Anxiety }\end{array}$} & Initi & 22.08 & 1.62 & 15 & 1.91 & 12.894 & \multirow[t]{2}{*}{4.00} \\
\hline & & 20.17 & 1.85 & 15 & & & \\
\hline \multirow{2}{*}{$\begin{array}{c}\text { Self } \\
\text { Confidence }\end{array}$} & & 21.83 & 2.36 & 15 & \multirow[t]{2}{*}{\begin{tabular}{|l|}
-1.84 \\
\end{tabular}} & \multirow[t]{2}{*}{16.316} & \\
\hline & Final & 23.67 & 2.18 & 15 & & & \\
\hline
\end{tabular}

Table -1 indicates that the obtained ' $t$ ' ratios were: 3.343 for VO2 $\mathrm{max}, 13.385$ for resting pulse rate, 11.222 for cognitive anxiety, 12.894 for somatic anxiety and 16.316 for self confidence. The obtained ' $t$ ' ratios on martial arts training group. When compared with the critical value of 2.20 for degrees of freedom of 11 it was found that the mean gains and mean losses statistically significant. Resulting of these confirm that six week practice of martial arts training produced a significant improvement in VO2 max (1.36; 
$\mathrm{p}<0.05)$, resting pulse rate $(2.58 ; \mathrm{p}<0.05)$, cognitive anxiety (2.91; $\mathrm{p}<0.05)$, somatic anxiety $(1.91 ; \mathrm{p}<0.05)$ and self confidence $(1.84 ; \mathrm{p}<0.05)$ statistically significant and explained its effect positively.

Table - 2 The difference between the results of the initial and final measuring the Control group

\begin{tabular}{|l|l|l|l|l|l|l|l|}
\hline Test & Measuring & Mean & Std.dev. & N & Diff. & t & sig \\
\hline \multirow{2}{*}{$\mathrm{Vo}_{2}$ Max } & Initial & 38.26 & 1.18 & 15 & 0.28 & 1.189 & .259 \\
\cline { 2 - 8 } & Final & 37.98 & 1.00 & 15 & & & \\
\hline \multirow{2}{*}{$\begin{array}{l}\text { Resting Pulse } \\
\text { Rate }\end{array}$} & Initial & 72.17 & 2.62 & 15 & 0.34 & 0.715 & .489 \\
\cline { 2 - 8 } & Final & 71.83 & 3.27 & 15 & & & \\
\hline \multirow{2}{*}{$\begin{array}{l}\text { Cognitive } \\
\text { Anxiety }\end{array}$} & Initial & 20.33 & 2.64 & 15 & 0.42 & 1.449 & .175 \\
\cline { 2 - 8 } & Final & 19.91 & 2.71 & 15 & & & \\
\hline Somatic Anxiety & Initial & 21.25 & 1.71 & 15 & 0.50 & 1.483 & .166 \\
\hline
\end{tabular}

\begin{tabular}{|l|l|l|l|l|l|l|l|}
\hline & Final & 20.75 & 1.95 & 15 & & & \\
\hline $\begin{array}{l}\text { Self } \\
\text { Confidence }\end{array}$ & Initial & 20.83 & 1.74 & 15 & -0.17 & 0.561 & .586 \\
\cline { 2 - 8 } & Final & 21.00 & 1.76 & 15 & & & \\
\hline
\end{tabular}

Table - 1 indicates that the obtained 't' ratios were: 1.189 for $\mathrm{VO}_{2}$ max, 0.715 for resting pulse rate, 1.449 for cognitive anxiety, 1.483 for somatic anxiety and 0.561 for self confidence. The obtained ' $t$ ' ratios on control group. When compared with the critical value of 2.20 for degrees of freedom of 11 it was found that the mean gains and mean losses statistically not significant. Resulting of these confirm that of control group a not significant improvement in $\mathrm{VO}_{2} \max (0.28$; $\mathrm{p}>0.05)$, resting pulse rate $(0.34 ; \mathrm{p}>0.05)$, cognitive anxiety (0.42; $\mathrm{p}>0.05)$, somatic anxiety $(0.50 ; \mathrm{p}>0.05)$ and self confidence $(0.17 ; \mathrm{p}>0.05)$ statistically not significant and explained its effect negatively.

Table - 3 Analysis Of Covariance Of Adjusted Test Means On Psycho Physiological Variables Of Male Basketball Players

\begin{tabular}{|c|c|c|c|c|c|c|c|c|}
\hline \multirow[t]{2}{*}{ Si. no } & \multirow[t]{2}{*}{ Criterion variables } & \multicolumn{2}{|c|}{ Adjusted Mean } & \multirow[t]{2}{*}{ Sum of variance } & \multirow{2}{*}{$\begin{array}{l}\text { Sum of } \\
\text { square }\end{array}$} & \multirow[t]{2}{*}{ df } & \multirow[t]{2}{*}{ Mean square } & \multirow[t]{2}{*}{ Obtained 'F'ratio } \\
\hline & & Martial arts & Control & & & & & \\
\hline \multirow[t]{2}{*}{1} & \multirow[t]{2}{*}{ VO2 max } & \multirow[t]{2}{*}{36.97} & \multirow[t]{2}{*}{38.00} & B/G: & 6.38 & 1 & 6.38 & \multirow[t]{2}{*}{$7.32^{*}$} \\
\hline & & & & W/G: & 18.31 & 21 & 0.87 & \\
\hline \multirow[t]{2}{*}{2} & \multirow[t]{2}{*}{ Resting pulse rate } & \multirow[t]{2}{*}{70.02} & \multirow[t]{2}{*}{72.31} & B/G: & 29.97 & 1 & 29.97 & \multirow[t]{2}{*}{$18.83^{*}$} \\
\hline & & & & W/G: & 33.42 & 21 & 1.59 & \\
\hline \multirow[t]{2}{*}{3} & \multirow[t]{2}{*}{ Cognitive anxiety } & \multirow[t]{2}{*}{18.75} & \multirow[t]{2}{*}{21.08} & B/G: & 24.11 & 1 & 24.11 & \multirow[t]{2}{*}{$26.17^{*}$} \\
\hline & & & & W/G: & 19.35 & 21 & 0.92 & \\
\hline \multirow[t]{2}{*}{4} & \multirow[t]{2}{*}{ Somatic anxiety } & \multirow[t]{2}{*}{19.75} & \multirow[t]{2}{*}{21.17} & B/G: & 11.36 & 1 & 11.36 & \multirow[t]{2}{*}{$13.32^{*}$} \\
\hline & & & & W/G: & 17.91 & 21 & 0.85 & \\
\hline \multirow[t]{2}{*}{5} & \multirow[t]{2}{*}{ Self confidence } & \multirow[t]{2}{*}{23.22} & \multirow[t]{2}{*}{21.44} & B/G: & 17.93 & 1 & 17.93 & \multirow[t]{2}{*}{$31.20^{*}$} \\
\hline & & & & W/G: & 12.06 & 21 & 0.57 & \\
\hline
\end{tabular}

* Significant at 0.05 level

The preliminary aim of analysis of covariance is adjusting the post test means for differences in the pre test means, and adjusted means are tested for significance. The F-ratio from testing the adjusted post test means among the two groups namely martial arts training group and control group on variables used in this present study is shown table 3.

The F-value needed for significant difference among the means of two groups for df 1,21 , was 4.32 at 0.05 level. The obtained F-ratios 7.32 for $\mathrm{VO}_{2}$ max, 18.83 for resting pulse rate, 26.17 for cognitive anxiety, 13.32 for somatic anxiety and 31.20 for self confidence it was found that the observed ' $F$ ' values on adjusted means of $\mathrm{VO}_{2} \mathrm{max}$, resting pulse rate, cognitive anxiety, somatic anxiety and self confidence. Were higher than the required critical value (4.32) therefore mean differences, among the two groups on adjusted means were statistically significant.

\section{Discussion of Findings}

The analysis of the results revealed that in the case of the experimental group, all the variables such as $\mathrm{VO}_{2} \mathrm{max}$, resting pulse rate, cognitive anxiety, somatic anxiety and self confidence improved as a result of the 6 week marital arts training. In the case of the control group, no changes were noticed in any of the selected variables during the same period. The results of this study further reveals that martial arts training improved cognitive anxiety, somatic anxiety and self confidence by over $8.81 \%, 8.40 \%$ and $8.06 \%$ respectively by finding significant differences in comparisons pre-test to posttest.

This study was expected to contribute to an understanding of the psychological value of Taekwondo. The study was also expected to provide more insight into the beneficial effects of Taekwondo training for both physical educators and Taekwondo trainees. Research suggests that Taekwondo training may have many psychological benefits, such as enhanced self-esteem, self-concept (Columbus \& Rice, 1991, cited from Kurian et al., 1993 ; Finkenberg, 1990), and reducing aggressiveness (Skelton, 1991). In the study of Kurian et al.
(1993), it was indicated that Taekwondo training could decrease scores on anxiety and increase scores on personal independence and ability to take a leadership role. Furthermore, Kurian et al. (1993) concluded that participation of Taekwondo training might be used as a therapeutic program. Finkenberg (1990) found that Taekwondo training was helpful for college men to build self-concept.

Taekwondo training elicited HR into $64.7-81.4 \%$ of HR maximum (\%HRmax). Moderate relative exercise intensities (64.7-69.4\%HRmax) were elicited by elastics, technical combinations, and step sparring. The remaining 5 training activities elicited hard relative exercise intensities (74.7$81.4 \%$ HRmax). Taekwondo training activities in this study seemed suitable for cardiovascular conditioning, although different training activities stressed the cardiovascular system to different degrees. Practically, this suggests coaches need to structure Taekwondo training sessions based not only on the technical and tactical needs of practitioners but also in a manner that enables sufficient cardiovascular conditioning for competition.

Several studies support the impact martial arts training has on reducing anxiety. Using college students in physical education classes, Foster (1997) found that compared to Aikido and golf, only karate decreased trait anxiety significantly as measured by the State-Trait Anxiety Inventory; however, there was no change on state anxiety. A study by Layton (1990) examining anxiety in karate students ages 16 to 54 from novices to 5 th degree black belt using the State-Trait Anxiety Inventory showed that non-black belt grades were significantly higher on both state and trait anxiety. With age controlled, it was found that the number of years of training was negatively related to both trait and state anxiety.

Trulson and Kim (1985) conducted a cross sectional study of Tae Kwon Do students using the Jackson Personality Inventory. Those students with less than one year of experience were found to be no different than the general population on several psychological measures, indicating that there was no selection occurring on entry into the martial art classes. As 
experience level in the martial art increased, students showed lower anxiety, a higher sense of responsibility, a decrease in willingness to take risks, they were less "radical", had increased self esteem, and were more socially intelligent. These trends were especially pronounced in the black belt levels. Other effects were seen in increased physical fitness, defence skills, self discipline, concentration, and respect.

\section{CONCLUSION}

The following conclusions were drawn from the results of the study:-

1. Results on individualized effect confirms positively and significantly the effect of martial arts training on selected psycho-physiological variables of basketball players who practiced with martial arts training, in addition to their traditional physical training, and

2. From the results of comparative effects, it was observed that martial arts training, used in the study, made desirable changes on selected psycho-physiological variables, compared to the basketball players of Control Group. By this, it was concluded that the desirable changes observed on $\mathrm{VO}_{2}$ max, resting pulse rate, cognitive anxiety, somatic anxiety and self confidence variables as compared to the players of Control Group.

\section{REFERENCES}

1. Chapman, C., Lane, A.M., Brierly, J.H. \& Terry, P.C. (1997). Anxiety, selfconfidence and performance in Tae Kwon-do. Perceptual \& Motor Skills, 85, 1275-1278.

2. Columbus, P. J., \& Rice, D. L. (1991). Psychological research on the martial arts: An addendum to Fuller's review. British Journal of Medical Psychology, 64, 127-135.

3. Cox, J. C. (1993). Traditional Asian martial arts training: A review. Quest, 45, 366-388.

4. Cox, R. H., Martens, M., \& Russell, W. D. (2003). Measuring anxiety in athletics: The revised Competitive State Anxiety Inventory-2. Journal of Sport \& Exercise Psychology, 25, 519-533.

5. Daniels, K., \& Thornton, E. W. (1990). An analysis of the relationship between hostility and training in the martial arts. Journal of Sports Sciences, 8, 95-101.

6. Donahue, J. J. (1994). Warrior Dreams: The Martial Arts and the American Imagination. Westport, CT: Bergin \& Garvey. Donnelly, P., \& Young, K. (1988). The construction and confirmation of identity in sport subcultures. Sociology of Sport Journal, 5(3), 223-240.

7 Duthie, R B. Hope, L \& Barker D.G. (1978). Selected personality traits of martial artists as measured by the Adjective Checklist. Perceptual \& Motor Skills, 47, 71-76.

8. Foster, Y.A. (1997). Brief aikido training versus karate and golf training and university students' scores on self-esteem, anxiety, and expression of anger. Perceptual \& Motor Skills, 84, 609-610.

9. Kurian, M., Caterino, L. C., \& Kulhavy, R. W. (1993). Personality characteristics and duration of ATA Taekwondo training. Perceptual and Motor Skills, 76(2), 363-366.

10. Layton, C. (1990). Anxiety in black-belt and nonblack-belt traditional karateka. Perceptual \& Motor Skills, 71, 905-906.

11. Layton, C. \& Moran, P. (1999). Effect of "group spell" upon Shotokan black-belt performance of Heian kata. Perceptual \& Motor Skills, 89, 493-494.

12. Martens, R., Vealey, R. S., \& Burton, D. (1990). Competitive anxiety in sport. Champaign, IL: Human Kinetics.

13. Thomas, J. R., Salazar, W., \& Landers, D. M. (1991). What is missing in $p<.05$ ? Effect size. Research Quarterly for Exercise and Sport, 62, 344-348.

14. Trulson, M. E. (1986). Martial arts training: A novel "cure" for juvenile delinquency. Human Relations, 39, 1131-1140.

15. Weinberg, R.S. \& Comar, W. (1994). The effectiveness of psychological interventions in competitive sports. Sports Medicine, 18, 406-418. 